\title{
HOMESCHOOLING NO BRASIL: AMPLIAÇÃO DO DIREITO À EDUCAÇÃO OU VIA DE PRIVATIZAÇÃO?*
}

\author{
Luciane Muniz Ribeiro Barbosa ${ }^{1}$
}

\begin{abstract}
RESUMO: Este artigo apresenta o debate sobre a temática do homeschooling, analisando-o como um direito individual de liberdade de escolha das famílias, sendo uma opção destas pelo ensino de seus filhos no âmbito privado. Aumenta o número de famílias brasileiras que optam por retirar seus filhos da escola e ensiná-los em casa, bem como se amplia o movimento em prol da mudança da legislaçáo para a normatização do ensino em casa no país. Questiona-se, então, o significado da educação dentro do contexto maior que envolve o Estado Democrático de Direito, bem como a educação como um bem público, com fins públicos e privados, diante da prática do homeschooling e suas possíveis implicaçóes para a privatização da educação.
\end{abstract}

Palavras-chave: Homeschooling. Direito à Educação. Privatização da Educação.

\section{HOMESCHOOLING IN BRAZIL: EXPANSION OF THE RIGHT TO EDUCATION OR MEANS OF PRIVATIZATION?}

ABSTRACT: This article presents the debate on the subject of homeschooling. It analyzes homeschooling as an individual right for the freedom of choice of families, being opted by these parents to privately educate their children. The number of Brazilian families who choose to withdraw their children from school and to teach them at home has been increasing, as the movement to change the homeschooling regulation legislation in the country has expanded. This article questions the meaning of education within the larger context in the Democratic State of Rights, as well as education as a public asset, with public and private purposes, considering the homeschooling practice and its possible implications for the privatization of education.

Keywords: Homeschooling. Right to Education. Privatization of Education.

\footnotetext{
*Parte deste texto foi apresentada no V Seminário de Educação Brasileira (CEDES/Unicamp), em 2015. O estudo foi realizado no âmbito da pesquisa de Doutorado, finalizado em 2013, com financiamento da FAPESP e CAPES.

${ }^{1}$ Universidade Estadual de Campinas, Faculdade de Educação, Departamento de Políticas, Administração e Sistemas Educacionais - Campinas (SP), Brasil. E-mai: lumuniz@unicamp.br DOI: 10.1590/ES0101-73302016157215
} 


\title{
HOMESCHOOLING AU BRÉSIL: EXTENSION DU DROIT À L'ÉDUCATION OU PAR L'INTERMÉDIAIRE DE LA PRIVATISATION?
}

\begin{abstract}
RÉSUMÉ:Cet article présente le débat sur la thématique du homeschooling, en l'analysant comme un droit individuel de liberté de choix des familles, étant une option de ces dernières par l'enseignement de leurs enfants dans le secteur privé. Le nombre de familles brésiliennes qui décident de retirer leurs enfants de l'école afin qu'ils suivent l'apprentissage à la maison augmente, et le mouvement pour le changement de la législation pour la normalisation de l'enseignement à la maison dans le pays. On se demande donc quel est le sens de l'éducation dans le contexte élargi qui englobe l'État Démocratique du Droit, ainsi que l'éducation comme un bien public, à des fins publiques et privées, par rapport à la pratique du homeschooling et de ses éventuelles conséquences pour la privatisation de l'éducation.
\end{abstract}

Mots-clés: Homeschooling. Droit à l'Éducation. Privatisation de l'Éducation.

\section{Introdução}

A

pós uma histórica e crescente reivindicação legal por ação estatal na ampliação da escolarização obrigatória para todos, mediante garantias como acesso à escola, condiçóes para permanência e conclusão dos estudos com qualidade, o Brasil se depara com uma "nova" problemática: o direito, reivindicado por algumas famílias, de que os filhos não frequentem a escola e estudem em casa, questionando a legitimidade do Estado ao estabelecer a compulsoriedade da educação escolar, bem como o papel da escola diante dos objetivos constitucionais para a educação.

Reconhecido legalmente e praticado em cerca de 63 países diferentes, o homeschooling ${ }^{1}$ tem se revelado um fenômeno crescente em diferentes regióes (VIEIRA, 2012). Segundo dados recentes da Associação Nacional de Educação Domiciliar (ANED) ${ }^{2}$, cerca de 2.500 famílias são praticantes do homeschooling no Brasil. Esta temática se difunde no país com ampla divulgação da imprensa sobre casos de famílias brasileiras que enfrentam problemas com a Justiça pela decisão de retirarem os filhos da escola. Além das demandas ao Poder Judiciário, a temática também é recorrente no Poder Legislativo, no qual se constata um histórico de apresentação de Projetos de Lei à Câmara dos Deputados, visando à alteração da legislação brasileira de modo a permitir e regulamentar o homeschooling no Brasil (Cf. BARBOSA, 2012). 
Para além deste debate nos âmbitos legislativo e jurídico, destaca-se outro argumento que permeia a temática, encontrado sobretudo na literatura internacional como uma das possíveis implicaçóes do homeschooling: a de que a escolha por essa modalidade de ensino estaria associada a uma tendência de valorizaçáo dos bens privados sobre os bens públicos, centrando-se nas questôes dos direitos individuais e benefícios privados da educação (LUBIENSKI, 2000).

Assim, apesar de o homeschooling ser um movimento frequentemente associado ao movimento da school choice na América do Norte, é possível avaliar que seu crescimento encontra-se relacionado, além de aos impactos do mercado nas reformas educacionais, à emergência e aumento de uma cultura florescente da "intensiva educação dos filhos", diante da qual é possível verificar o crescimento de uma oferta de ensino diferenciado e individualizado, lógica na qual se insere o homeschooling como o mais expressivo segmento da escolarização privada (AURINI e DAVIES, 2005).

O objetivo do presente artigo é analisar, diante do movimento crescente no Brasil em prol da normatização do homeschooling, os desafios presentes na garantia do direito à educação, questionando o significado da educação dentro do contexto maior que envolve o Estado Democrático de Direito, bem como a educação como um bem público, com fins públicos e privados, diante da prática do homeschooling e suas possíveis implicaçôes para a privatização da educaçẫo no país.

As análises aqui propostas resultaram de um percurso metodológico que incluiu a revisão da literatura internacional sobre a temática do homeschooling com enfoque nas discussóes sobre a privatizaçáo da educaçáo, a apreciação da legislaçáo nacional no que diz respeito ao direito à educação e à compulsoriedade da matrícula escolar, assim como o diálogo com os estudos, recentes e ainda escassos, de trabalhos que analisam a temática no Brasil e suas repercussões no âmbito legislativo e judiciário. Os resultados encontrados apontam para a necessidade de análise e acompanhamento do movimento a favor da regulamentação do homeschooling no Brasil, o qual acompanha a tendência de privatização da oferta de educação no país - acompanhada pelas políticas de escolha (Cf. ADRIÁO, 2015) - e passa a ser avaliado tanto como a ampliaçáo de um direito individual de escolha (da família), como a expressão máxima de privatização da educação.

\section{Homeschooling e o direito à Educação no Brasil}

Uma das questóes centrais no debate brasileiro sobre o homeschooling gira em torno da constitucionalidade de tal prática no país. Apesar da visão majoritária de sua inconstitucionalidade, verificou-se que ela é passível de contestação e não se revela como única. Assim, o estudo sobre a possibilidade de prática e de normatização do ensino em casa no Brasil requer uma análise dos aspectos jurídi- 
cos que envolvem o tema, suscitando a compreensão do que estabelece a legislação, do impacto das decisões judiciais já existentes sobre o tema, da repercussão dos Tratados Internacionais de Direitos Humanos ratificados pelo Brasil, assim como da pressão exercida pela população e pelas associaçóes em prol do movimento.

Considerando a redação do art. 205, da Constituição Federal de 1988 (CF/88), no qual o termo "estado" precede a palavra "família" ao estabelecer os objetivos da educaçáo, parte da doutrina passou a defender a prioridade do Estado sobre a família no dever pela educação escolar. Seguindo essa argumentação, ressalta-se também o $\$ 3^{\circ}$ do art. 205 ao determinar que "Compete ao Poder Público recensear os educandos no ensino fundamental, fazer-lhes a chamada e zelar, junto aos pais ou responsáveis, pela frequência à escola".

A legislação decorrente da Lei Maior também parece inclinar-se para uma prioridade do Estado na matéria educacional. A Lei de Diretrizes e Bases da Educação Nacional (LDB - Lei no 9.394/96) previu em seu art. $1^{\circ}$ que a educação abrange os processos formativos que se desenvolvem, entre outros espaços, na vida familiar; porém, no $\$ 1^{\circ}$ há o registro de que a educação escolar deve acontecer, predominantemente, por meio do ensino em instituiçóes próprias. O Estatuto da Criança e do Adolescente (ECA - Lei no 8.069/90) também deixa claro, em seu art. 55, que "Os pais ou responsável têm a obrigação de matricular seus filhos ou pupilos na rede regular de ensino", ressaltando esse dever também no art. 129, ao explicitar os deveres dos pais para com a educação: "V - obrigação de matricular o filho ou pupilo e acompanhar sua frequência e aproveitamento escolar".

No entanto, ainda que haja clareza, do ponto de vista legal, quanto à obrigatoriedade da matrícula em escolas, surgem questionamentos sobre as possíveis lacunas legislativas a favor do homeschooling. Dessa maneira, é possível verificar que os favoráveis ao ensino em casa no Brasil baseiam-se na CF/88 para defender, entre outros, que: o dever do Estado, no campo educacional, é supletivo e subsidiário ao dever da família; o art. 229 (que expressa o dever dos pais de assistir, criar e educar os filhos menores), bem como os artigos 205 e 206, concedem à família a garantia do direito fundamental, que lhe pertence, de escolher, livre e prioritariamente, o tipo de educação que deseja dar a seus filhos, visando aos fins proclamados na constituição.

Da análise minuciosa dos textos legais (BARBOSA, 2013), verifica-se que tanto os argumentos favoráveis quanto os contrários ao homeschooling baseiam-se não somente em artigos, mas também nos princípios constitucionais. Como consequência, cria-se uma situação de colisão de princípios diante da qual as decisóes têm sido tomadas pelo Poder Judiciário, tendo este apresentado interpretação predominante de que a prática de tal modalidade de ensino no Brasil é contrária ao contexto em que se insere a CF/88, bem como aos objetivos que esta estabelece para a educação dentro de um Estado Democrático de Direito. A ideia ainda predominante no país é a de que a educação como direito 
exige, na formação do cidadáo, o preparo para viver em ambiente democrático e republicano, o que supóe, no mínimo, o conhecimento das instituiçóes democráticas dos mecanismos de representaçáo e dos direitos e deveres inerentes à cidadania (RANIERI, 2009, p. 16),

formação esta que poderia ser prejudicada quando limitada ao ambiente familiar.

Entretanto, cabe ressaltar que esse entendimento não é unânime, visto que, quase uma década após a decisão do Superior Tribunal de Justiça, em 2001, contrária ao homeschooling no Brasil, uma família no estado do Paraná recebeu autorização do juiz local para sua prática, sujeita à verificação pelo Poder Público quanto ao cumprimento dos objetivos constitucionais e legais para com a educação das crianças, destacando-se a ideia de que importa alcançar tais objetivos, independentemente se pela via da instituição escolar ou outra (Cf. BARBOSA, 2013).

Ressalta-se também a presença constante do debate sobre o impacto, na ordem jurídica nacional, dos Documentos Internacionais para a proteção de Direitos Humanos, ratificados pelo Brasil ${ }^{3}$, que apresentam normas favoráveis à primazia dos pais na escolha do tipo de educação a ser dada aos filhos. $\mathrm{O}$ uso de tais documentos para defender o homeschooling não é algo recente; assim, as famílias brasileiras estariam acompanhando o histórico percorrido por outros países no processo de legalizaçáo de tal prática, apropriando-se da linguagem mais universal dos direitos, especificamente reunidos em três campos temáticos: liberdade de escolha; liberdade dos pais e direitos individuais (AURINI; DAVIES, 2005).

Por outro lado, o reconhecimento da educação compulsória nas leis internas da maioria dos países no mundo também se revela como reflexo dos Tratados Internacionais de Direitos Humanos, bem como da mudança de visão sobre a criança como sujeito de direito, trazida sobretudo pela Convenção Sobre os Direitos da Criança (TOMASEVSKI, 2001a, p. 25). Entretanto, para Tomasevski (2001b, p. 15), o cumprimento de tal obrigatoriedade requer um balanço entre direitos e deveres, liberdades e responsabilidades, orientadas pelas leis em geral e também pelas leis de direitos humanos, pois uma criança não pode ter o direito a uma educaçáo gratuita a menos que o governo seja capaz de aumentar os recursos nela investidos, assim como a educação não pode ser obrigatória, a menos que os pais aceitem que seus filhos têm o direito à educação.

A partir das características inerentes ao direito à educação no Brasil e, especificamente, considerando o contexto, os objetivos e princípios ${ }^{4}$ declarados na $\mathrm{CF} / 88$, surgem posiçôes favoráveis e contrárias ao ensino em casa no país. Os defensores argumentam que a educação (e sua escolha pelos pais) está associada à democracia, sendo a negação da prática do homeschooling uma ameaça ao caráter democrático do Estado brasileiro. Nessa perspectiva, o reconhecimento do 
direito ao ensino em casa mostrar-se-ia fator altamente positivo para um avanço da educação no Brasil democrático. Na avaliação do ministro Netto (2005), é necessária a aceitação do primado da família sobre a educação dos filhos como algo pertencente ao Estado Democrático de Direito; a obrigatoriedade da imposição do Estado sobre a dos cidadáos e da família significaria náo menos do que copiar modelos fascistas, nazistas ou totalitários.

Questiona-se, assim, o significado da educaçáo dentro desse contexto maior que envolve o Estado Democrático de Direito, bem como os valores e objetivos deste para com a educação, diante da prática do homeschooling. Esse modelo de Estado, por um lado, não objetiva acabar nem com os direitos individuais (como liberdade de escolha), tampouco com a dimensão individual dos direitos coletivos (como é o caso da escolha da educação). Por outro, ressalta os princípios republicanos e democráticos nele presentes e necessários para sua permanência enquanto Estado Democrático de Direito.

\section{Homeschooling e as fronteiras entre a ampliação de direitos e a privatização da educação}

As objeçóes mais recorrentes no debate sobre a possibilidade de normatização do homeschooling no Brasil centram-se sobretudo no papel da escola no que tange à socialização e à formação para a cidadania; entretanto, é possível reconhecer que tanto as experiências internacionais (baseadas em pesquisas teóricas e empíricas) como as nacionais (ainda que incipientes) revelam a necessidade de revisão de tais pressupostos, dirimindo o "mito" da falta de socialização e formação para a cidadania nas experiências do ensino em casa (Cf. BARBOSA, 2013).

Assim, apesar dos temas anteriormente apresentados não terem sido esgotados e demandarem estudos mais aprofundados, o debate sobre homeschooling e principalmente sobre a possibilidade de normatização de tal prática no Brasil acaba incorrendo em outras relevantes questóes relacionadas às fronteiras do direito à educação, bem como à privatização da educação. Estas decorrem sobretudo de dois aspectos: diante da escolha que os pais fazem ao transferir a educação de seus filhos da escola para o âmbito privado da família; sob a análise da privatização da oferta educacional no que se refere à introdução de políticas de escolha parental (choice), como as charter schools, os vouchers ou homeschooling (ADRIÃO, 2015, p. 37).

O primeiro aspecto desse debate, anteriormente mencionado, é encontrado principalmente na literatura internacional ao analisar as implicaçōes do homeschooling, tendo Lubienski (2000 e 2003) como um dos críticos mais severos nesse âmbito. De acordo com este autor, enquanto os pais optam por um ensino individualizado que atenda às necessidades particulares de seus filhos (uma prerrogativa privada que pode diminuir custo e maximizar oportunida- 
des), acabam deixando a instituiçáo escolar, sobretudo a escola pública e, em última análise, decidem investir em seus próprios filhos em detrimento de um investimento no coletivo, de um compromisso com o bem público que afeta diretamente a manutençẫo da democracia.

Ranieri (2009, p. 390) apresenta o "fenômeno da individuação" como um dos desafios do século XXI, sendo que este, em suas diversas manifestaçóes, acentua as singularidades individuais, "ampliando o campo das açóes individuais em detrimento das normas [...], dos valores, dos laços tradicionais de solidariedade e da complementaridade entre o público e o privado". Esse contexto é também analisado por Apple (2003, p. 217), ao defender que o movimento a favor do homeschooling reflete o crescimento da consciência privatizada em outras áreas da sociedade. Segundo o autor, trata-se de uma extensão da "suburbanização" da vida cotidiana, equivalente às comunidades muradas e privatização de bairros, praças e outros espaços que indicam uma "redoma", não relacionada somente à tentativa de fugir dos problemas da cidade, mas sim a uma rejeiçấo de toda a ideia da cidade.

Lubienski (2003, p. 175) corrobora essa análise e enquadra o homeschooling como parte de uma das maiores tendências, presente em muitos países, de privatização de partes da vida social que anteriormente foram pensadas como pertencentes à esfera pública. Reivindicaçóes sobre direitos e deveres parentais de moldar as experiências educativas das crianças, embora válidas, negligenciam o legítimo interesse público nesse processo, para o autor.

A discussão ressalta, então, não a importância ou invalidade dos potenciais benefícios do homeschooling, nem o fato de que a oferta pública de educação poderia ser reformada e aprimorada, se tomadas seriamente muitas das motivaçóes dos que ensinam em casa; mas sim que: defendendo os "direitos dos pais" e focando exclusivamente nos resultados individualizados dos filhos, simplesmente não se consegue enfrentar e resolver as preocupaçôes coletivas e, na pior das hipóteses, contribui-se para exacerbá-las (MONK, 2009, p. 6).

Tal análise insere-se, portanto, em um contexto mais amplo ao se admitir a educação como um bem público que tradicionalmente tem servido a fins públicos e privados. E, diante deste cenário, a substituição do sentido público e político da educaçáo por seu valor de mercado implica que a iniciaçáo em uma herança cultural pública

passa a ser concebida como a transmissão de um capital cultural privado, cujo valor pode ser aferido a partir de seu impacto em outras dimensôes da existência, em geral ligadas à produção ou ao consumo de novas mercadorias (CARVALHO, 2013, p. 86). 
Nesse contexto, o homeschooling é avaliado como a forma mais radical de privatização de um bem público, dado que os pais focam somente nos benefícios de seus próprios filhos, prejudicando os interesses e responsabilidades públicas e privatizando os aspectos sociais da educaçáo (assim como seus meios, controle e propósitos) para o mais restrito nível, que náo simplesmente o de sua localidade ou grupo étnico, mas ao nível mais atomizado do núcleo familiar (LUBIENSKI, 2000 , p. 215). Dentro de um pensamento neoliberal mais amplo sobre o papel do indivíduo nas sociedades de mercado, o homeschooling representaria uma séria tendência de retirada de esforços coletivos e privatização do controle na perseguição das vantagens individuais (LUBIENSKI, 2003, p. 168).

Entretanto, os defensores do homeschooling questionam tal análise. A defesa apresentada por eles é a de que não estariam prejudicando o potencial da produção democrática de um bem público, mas apenas reivindicando seus direitos democráticos liberais clássicos de serem livres de interferências, enquanto não necessariamente negam suas responsabilidades democráticas; eles estariam reconstituindo seus direitos no nível individual e familiar, contribuindo assim para a comunidade ao criar indivíduos autônomos (LUBIENSKI, 2000, p. 216).

As famílias favoráveis ao homeschooling também fazem referência às falhas no sistema escolar e apresentam críticas ao sistema educacional público como um modelo de produção de massa, que serve aos interesses do governo, atuando as escolas como simples meios para assegurar um controle social por parte do Estado, o que resulta em um conflito de interesses e ideologias e pode limitar as oportunidades de determinados grupos, além de apresentar falhas e fracassar no intento de cumprimento dos objetivos educacionais.

Contrapondo esses argumentos, Lubienski (2000, p. 216) ressalta que as concepçóes de democracia apresentam os direitos individuais acompanhados de responsabilidades civis: "a ideia de democracia se torna oca e pode entrar em colapso se indivíduos definirem democracia somente em termos de direitos individuais, negligenciando o bem público" (LUBIENSKI, 2000, p. 217). Riegel (2001, p. 109) corrobora essa visão, afirmando que quando os defensores do ensino em casa focam suas críticas na escola pública e evidenciam os aspectos negativos do sistema educacional público para argumentar que esse estaria falido e prejudicando seus filhos, eles esquecem que esta escola, como qualquer outra instituição pública em uma economia capitalista, é inerentemente contraditória. Assim, se para alguns estudantes a escola pode alienar e reforçar as desigualdades, para outros, a escola tem sido inquestionavelmente fonte de mobilizaçáo social.

Assumindo que a educação tem um papel importante no processo de diminuição das desigualdades e desvantagens entre os estudantes, cabe ressaltar que, se por um lado as instituiçóes repetidamente falham nesse intento, por outro, o homeschooling não somente é incapaz de resolvê-lo, mas destina-se a frustrá-lo. Em outras palavras, se as escolas muitas vezes agravam as diferenças sociais e eco- 
nômicas entre os alunos, a natureza pública dessas instituiçóes oferece a oportunidade de iluminar tais problemas; por outro lado, o homeschooling não somente tira tais questóes da arena pública, mas também solidifica o background familiar dos indivíduos como o principal determinante do futuro sucesso destes (LUBIENSKI, 2003, p. 175 e 176).

Sob a análise do segundo aspecto anteriormente mencionado, Lubienski (2000) avalia ainda a opção pelo homeschooling em detrimento da escola pública como consequência de um contexto maior de ênfase em um paradigma econômico (em detrimento do político), no qual se basearam as reformas educacionais da América do Norte, em que os defensores das charter schools, vouchers e outras formas de school choice reivindicaram o fazer educação mais como um bem privado a ser perseguido individualmente, a educação mais como um negócio, em esferas econômicas nas quais se sobressaem o discurso da maior eficiência e a "opção de saída"; tal fato remove a educação do paradigma democrático e político, não somente despolitizando a educação, mas exercendo sua "opção de saída" em prol de avanços individuais e contribuindo para reduzir a capacidade da escola de se aprimorar como uma instituição democrática. Dessa maneira, a educação pública seria negada tanto em seu papel como em seu potencial para sustentar um bem público diretamente (LUBIENSKI, 2000, p. 225 e 226). Ainda, é preciso reconhecer que o advento dos mercados educacionais que beneficiou os pais e alunos mais privilegiados, em detrimento dos pais e alunos negros e economicamente pobres, é o mesmo contexto em que se deve analisar as consequências da expansão do homeschooling (APPLE, 2003, p. 231).

Entretanto, retirar as crianças da escola pública não significa escapar dos problemas sociais e pessoais decorrentes do fato do sistema público ter sido renegado com suas carências (RIEGEL, 2001, p. 111). Assim, as escolas públicas frequentemente falham em muitas áreas; contudo, falham como instituição pública, o que significa que todos têm potencial para enfrentar essas questões (LUBIENSKI, 2000, p. 229).

Diante de tais argumentos, a problemática apresentada é a de que, no Brasil, boa parte das críticas apresentadas à escolha do homeschooling pode, no mesmo sentido, ser dirigida ao ensino privado: questóes relacionadas a um possível elitismo; enquadramento social e também a "opção de saída" da instituição escolar de pais articulados e socialmente influentes, onde suas vozes e escolhas poderiam ser usadas para ir além de melhorar as circunstâncias educacionais individuais e experiências de seus filhos e ter um impacto social mais amplo (MORTON, 2010, p. 55).

$\mathrm{Ou}$ seja, se os pais que optam pelo homeschooling recentemente vêm sendo confrontados com argumentos e críticas que relacionam sua opção por essa modalidade de ensino como um descompromisso com o bem público, estas também podem ser transferidas ao contexto de possibilidade de "escolha" pela escola 
privada (em detrimento da melhoria do sistema educacional público) e a expansão desse ensino. Assim, as apreciações realizadas sobretudo por Lubienski (2000; 2003) náo podem, sob esse aspecto, ser direcionadas apenas aos que optam pelo homeschooling, mas também aos que fazem a escolha pela escola privada.

Radicalizando o contra-argumento das famílias que defendem o homeschooling, se é possível, no Brasil, o "direito de escolha" entre a escola pública e a escola privada, não haveria razão para se proibir a opçáo pelo ensino em casa, desde que se cumprisse com os objetivos estabelecidos legalmente para a educação.

Assim, diante da reivindicação por normatização do homeschooling no Brasil como ampliação do direito à educação no que se refere ao direito de escolha dos pais, destaca-se o enfrentamento não somente de desafios jurídicos presentes na regulamentaçáo da oferta dessa modalidade de ensino, mas também outros de natureza política. Nesse cenário, uma primeira questão a ser apresentada diz respeito ao caráter prático e objetivo de tal normatização, gerando questionamentos não somente à forma, mas também à identificação da população a ser atendida por esse "direito". Pode-se afirmar que, no caso brasileiro, uma resolução inicial necessária ao processo de regulamentação do ensino em casa é considerada em parte crítica e obstáculo à sua efetivação: o reconhecimento de que a possibilidade de escolha e prática do homeschooling não se revela para todos, sendo limitada à determinada parcela da população que apresente condiçóes para realizá-la.

Até mesmo na América do Norte, onde o sistema de escolha torna-se cada vez mais popular e aceito, sendo o homeschooling uma opção educacional, pesquisadores insistem em afirmar que a "escolha" de fato não é real para todos: "A crença de que um pai sempre escolherá o tipo de educaçáo mais adequado para seu filho ignora o fato de que a escolha não é disponível gratuitamente a todos os pais. A noçáo de escolha dos pais ignora várias barreiras comuns", como tempo, dinheiro, interesses outros (FINEMAN, 2009, p. 13). Ou seja, os pais com menos recursos não possuem tanta "opção" de escolha, sendo mantidos fora desse sistema. Lubienski (2003, p. 173) observa que "esta é uma decisão de estilo de vida disponível apenas a quem pode renunciar a lucros e recursos para a educação de seus filhos".

No Brasil, dadas as altas taxas de desigualdades social e econômica entre a população, esse quadro poderia se agravar ainda mais, com uma parcela muito pequena dispondo de tempo, recursos e podendo manter um membro da família fora do mercado de trabalho para se dedicar exclusivamente ao ensino dos filhos em casa. Diante dessa situação, cabe a indagação de Cury (2006, p. 679) ao questionar se, no Brasil, não retornaríamos a um quadro por muito tempo existente no país: elites ensinando seus filhos em casa e revelando uma histórica negligência com o acesso de todos a uma escolarização institucionalizada. 
Soma-se a essa análise o fato de, no país, o acesso a espaços e bens culturais, educacionais e esportivos ainda ser limitado e escasso, o que se revela fundamental para a agenda e rotina das crianças e jovens que estudam em casa no que diz respeito à socialização fora do âmbito familiar e aprendizado dos conteúdos necessários para sua formação.

Dessa maneira, destaca-se a complexidade apresentada às autoridades públicas brasileiras diante do apelo para a normatizaçáo do ensino em casa no país enquanto um direito de escolha das famílias (que comprovem condições para realizá-lo). Acredita-se também que o problema agravar-se-ia ainda mais se, regulamentando tal prática, o Estado se deparasse com a necessidade de criação de políticas públicas e serviços para atender essa camada da população.

Para Boudens (2002, p. 19), a mera existência de fundamentação jurídica não seria razão suficiente para justificar a implementação de políticas públicas explícitas de apoio ao ensino em casa. Porém, é preciso reconhecer que, caso o ensino em casa no Brasil seja normatizado, necessariamente demandar-se-ão políticas que o regulamentem, suscitando, então, uma série de açóes e prestaçóes por parte do Estado a fim de atender a esse direito, bem como supervisionar sua realização. Diante dessa constatação, surgem as críticas quanto ao investimento de recursos públicos para atender a educação no âmbito privado (das famílias); nesse quesito estaria a possibilidade de atendimento de determinadas classes (com certo poder aquisitivo) em detrimento de outras (da grande maioria) que, no caso do Brasil, foram historicamente marginalizadas. Sob essa perspectiva, o agravamento da situação se daria caso as famílias que optam pelo ensino em casa passem a solicitar subsídios públicos (quer seja em termos de auxílio financeiro ou de requisição de serviços e materiais), a exemplo do que já acontece em alguns países.

Assim, baseados em uma possível interpretação de que ao Estado cabe a tarefa de financiar a educação de todos e ao mesmo tempo assegurar o "direito dos pais" na escolha do gênero de educação de seus filhos, poder-se-ia incorrer em um quadro em que o Estado financiaria também as possíveis convicçóes religiosas das famílias, provocando amplo (e recorrente) debate na educação brasileira sobre questóes concernentes à laicidade do Estado e à transferências de recursos públicos para a esfera privada.

Tal preocupação baseia-se nos dados relacionados à população que escolhe ensinar os filhos em casa na América do Norte e os dados incipientes sobre as famílias no Brasil (VIEIRA, 2012) ao revelarem a existência de grande quantidade de famílias religiosas, apesar da crescente diversidade de grupos que adotam o homeschooling, assim como suas diferentes e variadas motivaçôes (ROTHERMEL, 2003). Essa constatação incentiva o debate sobre as implicações do uso de recursos financeiros dos cofres públicos para subsidiar a escolha de alguns pais pelo ensino de caráter confessional para os filhos, e também sobre a possibilidade de se legalizar o direito de famílias fundamentalistas optarem pelo ensino em casa com o 
objetivo de isolamento social dos filhos, afastando-os de comportamentos e visões diferentes de sua religiáo, prejudicando assim a formação desses enquanto indivíduos e cidadãos pertencentes a uma coletividade.

Tais implicações, apesar de relevantes em caso de normatização do homeschooling no país, também se confrontam com o argumento da possibilidade de existência do ensino privado como opção para as famílias brasileiras. Nesse sentido, também é possível às famílias escolherem uma escola confessional (que pode limitar a visão de mundo dos estudantes e condicioná-los a determinados comportamentos compatíveis com sua crença religiosa), além do fato de que esta instituição pode, seja por meio de convênios ou concessões diversas, receber ou ser parcialmente financiada por recursos públicos.

\section{Considerações finais}

Diante do exposto, considera-se que o homeschooling ganha relevância como um movimento social, com fortes implicações políticas (RIEGEL, 2001), além da avaliação de que este aumenta não apenas como um fenômeno, mas como uma "revolução silenciosa", que além de acarretar problemas administrativos, suscita questóes sobre o sentido e a finalidade da educação em uma sociedade baseada em princípios democráticos, ressaltando o papel da criança nesse processo (MONK, 2009, p. 21).

O homeschooling também provoca questionamentos sobre a escola, seja ela pública ou privada. Rejeitando-a em sua estrutura e forma de funcionamento, as famílias que optam pelo ensino em casa apontam a necessidade de se repensar o papel e a existência dessa instituição, ameaçando as representaçóes coletivas sobre ela, tão diluídas no cotidiano das pessoas. Essa representação que se criou sobre a escola "é transmitida e transformada conscientemente pela dinâmica social, até parecer algo dado e espontâneo sobre o qual convém sempre discutir, ainda que seja apenas para reafirmar seu valor, insuflando força a essa representação" (SACRISTÁN, 2001, p. 12, grifos do autor).

Nesse sentido, a reivindicação pela normatização e a própria prática do homeschooling no Brasil nos oferece a oportunidade de indagar, após séculos de entendimento sobre a escola como local de ensino, se de fato essa instituição é o lugar ideal para se educar: é possível alcançar uma educação de qualidade que cumpra os objetivos legalmente previstos na escola? A escola é o espaço ideal para a educaçáo que desejamos às crianças e jovens brasileiros, inspirada nos princípios de liberdade e nos ideais de solidariedade humana? É possível formar, na escola, cidadãos ativos com autonomia para satisfazer suas necessidades como indivíduos e participar da coletividade em prol da manutenção de uma sociedade democrática e buscando-se a qualidade do exercício dessa democracia? 
As famílias praticantes do homeschooling respondem a essas questôes pontuando que é possível responder à ineficiência da escola (pública e privada) ensinando os filhos em casa e formando-os bons cidadáos. De outro lado, Fineman (2009, p. 16) propóe que a solução para o dilema educacional atual seria tornar a educação pública obrigatória e universal; assim, o interesse expressivo dos pais complementaria essas instituições, nas quais as liçôes básicas e fundamentais seriam ensinadas e vividas por todas as crianças: sobretudo a de que devemos lutar juntos para nos definirmos como um coletivo e como indivíduos. Para a autora, se os pais não pudessem escolher (e "comprar") a forma de educar seus filhos fora de um sistema público, eles começariam a compartilhar a ideia de que devemos todos estar preocupados com as oportunidades de todas as crianças e nấo apenas com as da nossa própria.

Contudo, se inseridos no contexto de um Estado Democrático de Direito, em que a própria $\mathrm{CF} / 88$, refletindo os ideais democráticos e republicanos dessa sociedade, não aceitaria a ideia de uma educação pública compulsória e universal, sem a liberdade da iniciativa privada na oferta educacional, defende-se que todo o debate e implicações produzidas pelo crescente fenômeno do homeschooling no Brasil resultam em esforços em diferentes vertentes (não necessariamente opostas e concorrentes) como: a exigência de uma reforma na estrutura da instituição escolar; a aceitaçáo de que é possível os pais optarem pelo ensino em casa, normatizando-o; a rejeição total da ideia do ensino em casa ou mesmo da escola.

Reconhece-se que a incipiência e complexidade do debate sobre o tema no país revelam a necessidade de uma agenda de pesquisas que aprofundem os estudos a ele relacionados. Compreende-se também a existência de várias dimensôes presentes nesse debate: em termos de direitos; de políticas públicas; de projeto de sociedade; de valores e moral; entre outros; assim, simplesmente apresentar um posicionamento polarizado como favorável ou contrário normatização do homeschooling no Brasil pode levar à não contemplação da análise de algumas dessas importantes dimensóes. Em certo sentido, responder aos desafios presentes no enfrentamento do tema no país envolve a decisão por uma das vertentes que se deseja que o debate assuma.

Partindo desta defesa, reconhece-se como válida a busca dos pais que ensinam os filhos em casa por uma educação de qualidade, bem como as críticas que esses apresentam à ineficiência da instituição escolar perante o cumprimento dos objetivos constitucionalmente previstos para a educação; nessa perspectiva, a normatizaçáo de tal modalidade de ensino poderia ser avaliada como uma ampliação do direito à educação, no que se refere à sua interligação ao direito de escolha dos pais, diante da já existente possibilidade de escolha pelo ensino privado.

Contudo, o debate em torno deste tema no país exige também a necessidade de não dissociação da análise do histórico da educação no Brasil, 
bem como das características culturais, sociais e econômicas do país. Destas, depreende-se que, enquanto a temática da compulsoriedade da educação escolar no Brasil foi encarada por alguns como cerceadora da liberdade dos pais em ensinar seus filhos em casa, para uma grande maioria ela foi vista como uma conquista e um instrumento utilizado para defender o direito das crianças à educação, no enfrentamento de problemas socioeconômicos que as excluíam do acesso à escola (como o trabalho infantil, por exemplo). Assim, suscitar o debate sobre a compulsoriedade da educaçáo escolar versus o ensino em casa no Brasil implica reconhecer a existência de grandes desafios que evidenciam, por um lado, a necessidade de garantia de direitos individuais das famílias e, por outro, os inegáveis avanços que a ampliação do acesso à escola para camadas antes excluídas trouxe para o processo de democratizaçáo do ensino no Brasil (Cf. BEISIEGEL, 2005).

Desse modo, compartilha-se a visão de Boudens (2000, p. 15) de que as argumentações e decisões em relação à oficialização e prática do homeschooling no país tratam-se muito menos de natureza jurídica e mais de natureza política; sobretudo, do posicionamento político que se assume em prol do direito à educação de todos.

Pelos desafios aqui elencados e os argumentos e implicaçóes deles decorrentes, depreende-se que tanto a normatização quanto a implementação de políticas públicas para o ensino em casa no Brasil demandaráo do Estado uma série de esforços e investimentos no que diz respeito à garantia e supervisão quanto ao cumprimento do direito à educação. Assim, enquanto postura assumida diante de um projeto de sociedade que se deseja construir, defende-se a concentraçáo de esforços e recursos (por parte do Estado e da sociedade) a uma urgente reforma no sistema educacional, especialmente o público, visando a uma educação de qualidade que atenda aos objetivos constitucionalmente previstos.

\section{Notas}

1. Neste trabalho, o termo é utilizado na versão da língua inglesa ou traduzido por "ensino em casa".

2. Disponível em: www.aned.org.br

3. Trata-se de: Declaraçáo Universal dos Direitos Humanos (1948), o Pacto Internacional dos Direitos Econômicos, Culturais e Sociais (1966), a Convenção Americana de Direitos Humanos (1969) e a Convenção sobre os Direitos das Crianças (1989).

4. Os princípios, chamados também de "mandatos de otimização" são "normas constitucionais que se distinguem das regras por determinarem que os valores ou os fins que enunciam sejam realizados na maior medida possível, dentro das possibilidades jurídicas, fáticas e econômicas existentes" (RANIERI, 2009, p. 244). 


\section{Referências}

ADRIÃO, T.M.F. Dimensóes da privatização da educação básica no Brasil a partir de 1990: Um diálogo com a produção acadêmica. Tese (Livre-docência). Faculdade de Educação, Universidade Estadual de Campinas, Campinas, 2015.

APPLE, M.W. Fora com todos os professores: a política cultural do ensino doméstico. In: Educando à Direita: Mercados, Padrôes, Deus e Desigualdade. São Paulo: Cortez, 2003.

AURINI, J.; DAVIES, S. Choice without markets: home schooling in context of private education. British Journal of Sociology of Education. v. 26, n. 4, p. 461-474, set., 2005.

BARBOSA, L.M.R. Propostas que visam à legalização do ensino em casa no Brasil. Revista de Direito Educacional, v. 3, n. 5, p. 41-58, jan./jun., 2012.

. Ensino em casa ou na escola? Respostas do Poder Judiciário brasileiro. Cadernos Cenpec, v. 3, n. 1, p. 1-12, set., 2013.

Ensino em casa no Brasil: um desafio à escola? Tese (Doutorado em Educação). Faculdade de Educação, Universidade de São Paulo, São Paulo, 2013.

BEISIEGEL, R. A qualidade do ensino na escola pública. Brasília: Liber Livro, 2005.

BOUDENS, E. Ensino em casa no Brasil. Brasília: Câmara dos Deputados, 2002.

BRASIL. Constituição da República Federativa do Brasil de 1988. Disponível em < $\underline{\text { http:// }}$ www.planalto.gov.br/ccivil 03/constituicao/constituicao.htm>

. Lei no 8.069, de 13 de julho de 1990. Dispóe sobre o Estatuto da Criança e do Adolescente e dá outras providências. Disponível em <http://www.planalto.gov.br/ ccivil_03/leis/18069.htm>

Lei no 9.394, de 20 de dezembro de 1996. Fixa diretrizes e bases da educação nacional. Disponível em <http://www.planalto.gov.br/ccivil 03/leis/19394.htm>

CARVALHO, J.S.F. Reflexôes sobre educação, formação e esfera pública. Porto Alegre: Penso, 2013.

CURY, C.R.J. Educação escolar e educação no lar: espaços de uma polêmica. Educação e Sociedade. Campinas, v. 27, n. 96, p. 667-688, out. 2006.

FINEMAN, M. Taking Children's Interests Seriously. Public Law \& Legal Theory Research. Emory Public Law Research Paper n. 09-75, 2009.

LUBIENSKI, C. Whither the Common Good? A Critique of Home Schooling. Peabody Journal of Education, v. 75, n. 1\&2, p. 207-232, 2000.

A Critical View of Home Education. Evaluation and Research in Education, v. 17, n. 2\&3, p. 167-178, 2003.

MONK, D. Regulating home education: negotiating standards, anomalies and rights. Child and Family Law Quarterly, v. 21, n. 2, p. 155-184, 2009.

MORTON, R. Home education: construction of choice. International Electronic Journal of Elementary Education. v. 3, n. 1, out., 2010. 
NETTO, D.F. Aspectos constitucionais e infraconstitucionais do Ensino Fundamental em casa pela família. Brasília: Supremo Tribunal de Justiça, 2005.

RANIERI, N.B.S. O Estado democrático de direito e o sentido da exigência de preparo da pessoa para o exercício da cidadania, pela via da educação. Tese (Livre-docência). Faculdade de Direito, Universidade de São Paulo, São Paulo, 2009.

RIEGEL, S. The homeschooling movement and the struggle for democratic education. Studies in Political Economy. v. 65, 2001.

ROTHERMEL, P. Can we classify motives for home education? Evaluation \& Research in Education. v. 17, n. 2\&3, 2003.

SACRISTÁN, G. A Educação Obrigatória: seu sentido educativo e social. Porto Alegre: Artmed, 2001.

TOMASEVSKI, K. Free and compulsory education for all children: the gap between promise and performance. In: Right to Education Primers, n. 2. Gothenburg, Novum Grafiska AB, 2001a.

Human rights obligations: making education available, accessible, acceptable and adaptable. In: Right to Education Primers, n. 3. Gothenburg, Novum Grafiska AB, 2001b. VIEIRA, A.O.P. "Escola? Não, obrigado": Um retrato da homeschooling no Brasil. Monografia (Graduação). Instituto de Ciências Sociais, Universidade de Brasília, 2012.

Recebido em 03 de dezembro de 2015.

Aprovado em 15 de fevereiro de 2016. 